\title{
Perceptions of physical activity and technology enabled exercise interventions among people with advanced chronic kidney disease: a qualitative study
}

\author{
Mary Beth Weber ${ }^{1 *}$, Susan Ziolkowski ${ }^{2}$, Ahad Bootwala ${ }^{1,3}$, Alan Bienvenida ${ }^{1,3}$, Shuchi Anand ${ }^{2 \dagger}$ and \\ Felipe Lobelo ${ }^{1,3+}$
}

\begin{abstract}
Background: Exercise improves health outcomes and quality of life in persons with chronic kidney disease (CKD). The numbers of persons with advanced CKD meeting physical activity guidelines however is low. We undertook a qualitative study of men and women aged 36-74 from various race/ethnic populations with advanced CKD not requiring dialysis to describe their experiences and opinions around prior physical activity, motivating factors for and barriers to exercise, and perceptions of exercise-promoting technology and group-based programming designed to improve physical activity levels.
\end{abstract}

Methods: Nineteen persons with advanced CKD not requiring dialysis were interviewed at two high volume nephrology clinics enriched with racial/ethnic minority patients (Emory University and Santa Clara Valley Medical Center). We used thematic analysis to identify dominant themes $(n=4)$ and subthemes $(n=19)$ around exercise experience, barriers, motivators, views, and preferences.

Results: Four dominant themes and 19 subthemes were identified. The most common motivators to exercise included physical and mental health benefits, appearance, improvement in energy levels, and potential social interaction in group-based programs. Common barriers included health concerns, particularly complications related to other co-morbidities, as well as time and transportation constraints. Participants were skeptical of exercise programs solely reliant on technology.

Conclusions: The use of group-based exercise programs may motivate persons with CKD to increase exercise levels, while programs entirely based on technology may be less effective.

Keywords: CKD, Exercise, Type 2 Diabetes, Pre-dialysis, Physical activity

*Correspondence: mbweber@emory.edu

†'Shuchi Anand and Felipe Lobelo are co-senior authors.

${ }^{1}$ Hubert Department of Global Health, Rollins School of Public Health, Emory University, 1518 Clifton Road, NE, MS 1518-002-7BB, Atlanta, GA, USA

Full list of author information is available at the end of the article

\section{Introduction}

Physical activity (PA) is inversely related to mortality, quality of life, and physical functioning in persons with chronic kidney disease (CKD) [1-6]. Individuals with CKD should achieve at least $150 \mathrm{~min} /$ week of moderate intensity PA [7]. However, due to low exercise levels, nearly $95 \%$ of individuals starting dialysis have physical 
fitness levels below the 20th percentile for the general population [8].

Understanding barriers to, views of, and motivations for PA among people with CKD is key to designing acceptable and feasible interventions tailored to the needs of this diverse and highly co-morbid population. A few studies explored these topics in persons with end stage kidney disease [9-12], but less is known about exercise views among those with CKD not on dialysis. Groupbased exercise programming and technology-based fitness tools (e.g., smartphone applications, wearable fitness trackers) have been shown to overcome PA barriers and improve knowledge and activity levels [13-20]. More information is needed to understand perceptions of these proven exercise program components among people with CKD not on dialysis and provide a more nuanced picture of how to design exercise programs for this population.

Herein, we report the results of a qualitative, formative investigation of participant views and experiences to inform a technology enabled, group-based, patient-centered exercise program for persons with CKD at two clinical sites. The aim of this analysis is to describe the results of the in-depth interviews, specifically participants': 1) current and previous exercise experiences; 2) knowledge, barriers and motivators for PA; 3 ) views and current use of PA promotion technologies; and 4) perceptions of group-based exercise training programs. We conclude by discussing how this information can inform the design of exercise programming for people with CKD.

\section{Materials and methods}

\section{Participants and recruitment}

Participants were recruited from nephrology clinics at Emory University (Atlanta, GA) and Stanford University/ Santa Clara Valley Medical Center (San Jose, CA) as part of the "Exercise is Medicine" clinical research trial designed to improve PA levels in ethnic minority patients with advanced CKD (NCT \#NCT03311763) [21]. The study was approved by Emory University (IRB\#00099894) and Stanford University (IRB\#43198) Institutional Review Boards (IRB), and all methods were performed in accordance with the relevant IRB guidelines and regulations. Participants (Table 1) were recruited for the parent study with a screening questionnaire at a nephrology clinic visit, in-clinic fliers, and provider referrals. All recruited individuals were eligible for the formative, indepth interviews, and study coordinators invited information-rich individuals as they enrolled in the parent study. In order to capture differences in exercise experiences and views across in men and women and participants with or without diabetes status, study coordinators kept a rolling tally of participants these factors and sampled evenly from these subpopulations. These stratifications were selected because: (a) differences in physical activity are well documented by sex [22]; and (b) clinical guidelines for diabetes and prediabetes recommend exercise as part of clinical management for patients which could affect experiences of these participants [23, 24]. All approached participants agreed to be interviewed. Participants provided written informed consent before study enrollment and additional oral consent before their interview.

The research team developed the semi-structured interview guide internally (Supplement 1). An initial draft of the guide was created to include questions on topics of interest for intervention development; the research team then reviewed the guides, adding relevant probes and additional questions. The guide was then pilot tested internally through practice interviews with study team members and final edits were made to ensure clarity of questions and overall interview flow. Interviews were conducted by individuals trained on qualitative methods and the study tools (male graduate research assistants with extensive research experience [Emory] and a female project coordinator who was new to qualitative interviewing [Stanford]). Interviewers had no prior interaction with interview participants. Interviews lasted $30-50 \mathrm{~min}$ and were conducted at the clinic or by phone based on participant request. Key topics of discussion were (1) PA experience; (2) motivating factors for exercise; (3) exercise barriers; (4) barriers to exercise-promoting technologies; and (5) feedback on planned group-based exercise

Table 1 Inclusion and exclusion criteria of study participants

\begin{tabular}{ll}
\hline Inclusion Criteria & Exclusion Criteria \\
\hline Able to provide informed consent in English & Diagnosed mental health disorder \\
Non-wheel chair bound & Alcohol or drug abuse \\
Not yet on dialysis & No fixed address or contact details \\
Aged $30-80$ years & Unstable angina or unstable arrhythmias \\
No plans to move during the study period & Lack of access to internet \\
Interested in becoming more physically active over the next six months & Other concerns stated by the patient's nephrologist \\
\hline
\end{tabular}


programming. Interviews were audio-recorded, and field notes were added during transcription. The planned sample size was 20 interviews, 5 in each sex-diabetes strata (males with diabetes; females with diabetes; males without diabetes; and females without diabetes). The sample size was selected based on budgetary and time factors; however, there is support from the literature that a sample of this size is sufficient for reaching saturation [25]. In fact, interviews were stopped prematurely at the Stanford site, because ongoing review of the data indicated that there was already saturation of both codes and code meaning, [25] with no new themes emerging and no novel information being reported by participants. Participants were interviewed once and were not contacted to review transcripts or data interpretation.

\section{Analysis}

Verbatim transcripts (Supplement 2) from interview audio-recordings were reviewed to create an initial codebook highlighting key deductive and inductive themes. This initial codebook was shared with co-investigators, refined, and finalized. The final codebook included 4 themes (all deductive) and 19 subthemes (a mix of inductive and deductive). The codes corresponding to the themes/subthemes were as follows: PA Experience/Current Activity, Past Activity, Apps, Advice from Doctor, Inability to Be Active, and PA for CKD; Barriers/Health, Individual, Person, Structural, and Tech; Program Components/Trainers, Logistics, and Design; and Facilitators/
Motivators, Appealing, Desire, Benefits, and Outcomes. Data were coded by one investigator (MBW) and manipulated using MaxQDA (Verbi software). Data was analyzed using thematic analysis whereby thick descriptions were developed for each subtheme, noting differences and similarities across participant demographics (e.g., male vs. female, self-reported active vs. non-active, study sites, diabetic vs non-diabetic participants). Throughout the analysis, including manuscript preparation, the data ware revisited to ensure results were consistent with the textual data.

\section{Results}

Nineteen in-depth interviews were conducted across the two sites (11 at Emory, 8 at Stanford, Table 2). Participants did not discuss race or ethnicity as factors affecting any of the topics discussed, and unless otherwise noted, results did not vary by age, sex, site, or CKD type (diabetic or nondiabetic).

\section{Physical activity experiences}

Participants' current and past activity ranged from sedentary to running several miles daily. Disease or pain limited physical functioning and independence for four participants. Most participants reported a decline in activity after age 40 . Self-described "exercisers" reported more consistent activity patterns and types over time and more enjoyment with current activities.

Table 2 Demographic and Health Characteristics of Study Participants

\begin{tabular}{|c|c|c|c|}
\hline \multirow[t]{2}{*}{ Variable $^{a}$} & \multicolumn{2}{|l|}{ Interview Site } & \multirow[t]{2}{*}{ Total } \\
\hline & $\begin{array}{l}\text { Emory } \\
(n=11)\end{array}$ & Stanford $(n=8)$ & \\
\hline Sex, Male & $4(36 \%)$ & $4(50 \%)$ & $8(42 \%)$ \\
\hline \multicolumn{4}{|l|}{ Race/Ethnicity } \\
\hline Asian & $0(0 \%)$ & $3(38 \%)$ & $3(16 \%)$ \\
\hline Black/African American & $8(73 \%)$ & $1(13 \%)$ & $9(47 \%)$ \\
\hline Hispanic & $1(9 \%)$ & $1(13 \%)$ & $2(11 \%)$ \\
\hline White & $2(18 \%)$ & $2(25 \%)$ & $4(21 \%)$ \\
\hline Other/Declined & $0(0 \%)$ & $1(13 \%)$ & $1(5 \%)$ \\
\hline Age; Mean \pm SD (Range) & $58.5 \pm 11.3(36-71)$ & $62.4 \pm 7.6(48-74)$ & $60.2 \pm 10.2(36-74)$ \\
\hline \multicolumn{4}{|l|}{ Employment Status } \\
\hline Employed, Full Time & $2(18 \%)$ & $3(38 \%)$ & $5(26 \%)$ \\
\hline Employed, Part Time & $2(18 \%)$ & $1(13 \%)$ & $3(16 \%)$ \\
\hline Retired & $6(55 \%)$ & $3(38 \%)$ & $9(47 \%)$ \\
\hline Unemployed & $1(9 \%)$ & $1(13 \%)$ & $2(11 \%)$ \\
\hline Diabetic CKD ${ }^{\mathrm{a}}$ & $3(33 \%)$ & $6(75 \%)$ & $9(53 \%)$ \\
\hline eGFR; ${ }^{\text {a }}$ Mean \pm SD (Range) $\mathrm{ml} / \mathrm{min} / 1.73 \mathrm{~m}$ & $34.6 \pm 10.5(18-52)$ & $19.3 \pm 10.3(6-40)$ & $26.9 \pm 12.8(6-52)$ \\
\hline
\end{tabular}

a type of CKD missing for two Emory participants; Baseline eGFR missing for three Emory participants; Data presented as Number (percent) unless otherwise indicated SD Standard deviation, CKD Chronic Kidney Disease, eGFR Estimated glomerular filtration rate 


\section{Perceived benefits and motivating factors for exercise}

Perceived benefits (positive outcomes of exercise) and motivating factors (reasons participants are or desire to be more active) for exercise are shown in Table 3. Exercise helped participants manage co-morbidities (e.g., heart conditions, lupus, arthritis, and age-related stiffness), and three men believed exercise increase life expectancy. Participants reported that exercise was important for CKD; as one man shared, "Since I think the most driving factor of kidney disease is high blood pressure, I am thinking that exercise is like the best medicine that might be made for it." Participants understood that exercise would not cure their disease; however, several participants talked about how exercise made you stronger for dialysis.

CKD diagnosis was not a motivating factor for any participant to start exercising; however, a few participants did later understand that their activity could be help them manage their condition. For example, one woman shared:

\section{When I was first diagnosed ... the doctor at that time told me that ... this is something that was gonna be going on the rest of my life. So, it, so I didn't think there was anything I could do to change the results of the diagnosis ... . when I started walking, I didn't think about, you know, it helping kidney disease or having any effect on kidney disease.}

Furthermore, participants spoke about wanting to remain mobile and independent: "Because if you don't walk, you

Table 3 Perceived benefits and motivating factors for exercise in people with chronic kidney disease

\begin{tabular}{ll}
\hline Benefits & Motivating Factors \\
\hline Physical Health & $\begin{array}{l}\text { Improve health } \\
\text { Opportunity to be social } \\
\text { Reduction in blood pressure }\end{array}$ \\
Heart health & $\begin{array}{l}\text { Desire to reach goals } \\
\text { Weight loss/ maintenance } \\
\text { Musculoskeletal health }\end{array}$ \\
Pulmonary health & Improved flexibility \\
Lower cholesterol & \\
Reduction in medication use & \\
Improvement of other co-morbidities & \\
Reduce fall risk & \\
Delay dialysis & \\
Mental Health & \\
Stress reduction & \\
Reduce depression & \\
Improve mood & \\
Aid in focus & \\
Appearance & \\
Energy and Endurance & \\
Improved sleep &
\end{tabular}

won't be able to walk pretty soon. ... if I get on dialysis, I want to still be able to walk."

For one-third of participants, reaching PA or weight goals was an important motivator. For some participants, seeing progress towards goals was internally motivating, while others responded to the feedback they received from others. For women, weight loss was discussed in terms of physical appearance (being smaller, looking more youthful, etc.), as shown in this quote: "Once I saw the weight coming off and people was giving me compliments and, and I just felt good." For men, however weight loss was described as it related to improvements in physical function (increasing flexibility, mobility): "I believe that if I lost weight, I would be more flexible .... Because as you know getting up and down in a chair... you know just moving around."

\section{Barriers to exercise}

Health-related issues were the most frequently discussed barrier to being active. Participants cited multiple comorbidities and secondary CKD complications including arrhythmia, asthma, urinary tract infections, gout, overweight/obesity, arthritis, hypertension, neuropathy, mental health, and musculoskeletal issues. Participants were sometimes reluctant to exercise or increase exertion because of fear of pain or causing "flare-ups." Participants' medications made them "really fatigued ... I didn't feel like going to the gym. I didn't like to do anything." Except in the case of advanced disease, CKD was not identified as the dominant health-related barrier to exercise. Participants who believed their chronic conditions were well-managed stated that health was no longer a barrier to being active.

Internal (self-imposed) barriers, including feeling too busy to exercise, irregular schedules, having no time scheduled for PA, and finding available options uninspiring or not appropriate (too easy or too hard), were mentioned by most participants. For retired participants, prioritization of exercise was needed, since time was no longer a barrier: "I need to ... have the discipline to essentially treat exercise like it was you know, one of the more important tasks that I have to do each day." Other participants stated that they did not like exercise or felt like it took "a lot of effort" to do it; although this was not thought to be an insurmountable obstacle.

Over half of participants mentioned external exercise barriers. Men mentioned work-related issues such as inactive office job, long hours or commutes as barriers to exercise. Although women also stated that time was a barrier, work/work hours were not specifically mentioned. A few women mentioned specific events that were making it difficult to find time for exercise (e.g., a recent move). However, most women referred to being 
generally busy ('I'm usually involved in other things, you know, and I'm not able to be consistent doing it."), being too distracted by other activities ("I can waste a lot of time ... .that's one of my barriers to exercise in general"), or late nights ("Because I like the mornings [to exercise], but lot of times, if I like I have a bible study late at night.. and uh.. I go to bed late so ... I wind up getting up late."). Other barriers mentioned by one or two participants were sleep, weather, transportation, distance to facilities, and family members discouraging PA.

Although not specified as a barrier, almost all participants did not recall getting detailed advice about exercise from their physician. As one woman shared, "I don't recall, you know, having any conversations concerning, you know, exercising." There was some variability by study site, with Georgia participants being more likely to remember hearing something about PA from their doctor, while participants in California reported that their doctors' advice was more nutrition and weight loss focused. With additional probing, participants mentioned getting general advice to increase PA but no information on how to implement an exercise routine ("Well, you know, honestly, I think he asked me about it, but um, no direct instructions"). There were a few positive deviants, with two participants receiving more detailed advice ranging from an exercise brochure to gym and physical therapy referrals.

\section{Use and barriers of exercise-promoting technology}

Despite some participants expressing an eagerness or willingness to try technological solutions for increasing PA (e.g., wearable activity trackers, mobile phone health applications), few had used these tools in the past and the majority discussed technology-specific barriers. Existing applications were not tailored to them: "That's the biggest problem with apps, there's no true app that's made for someone that has a disability or health issue, they're all made for healthy people." Several women were uncomfortable or unskilled with technology, most relying on family members to set up or use computers, tablets, or the internet. Some men resisted smartphones or other devices because of the cost or not wanting to be "a slave to technology." Two men expressed dissatisfaction with a specific fitness application that works with a wearable device, stating that it was "poorly designed," not intuitive, and "a little bit techy." Two women did not like wearable devices for aesthetic reasons. Participants were not motivated to use technology long-term: "Well I had actually gotten it for, to monitor my um, heart rate and pulse and stuff, when I first um, got sick. ... But um, when I finally mellowed off, it [use of technology] did too."

\section{Group-based programming}

Most participants recalled fondly a time they were active, with the most favorable memories typically involving social activities (athletics, dancing, running groups), and an opportunity to be more social was the second most widely discussed motivator for PA. Participants discussed how group exercise helped overcome barriers, was more fun, and improved mental health. Also, seeing others be active, particularly similar individuals, encouraged participants to do more and try different activities: "And like I said, I think other people can motivate you too ... just looking at the other people."

Participants felt that a group exercise program specifically for patients with CKD could improve general and specific health (e.g., cholesterol levels, blood pressure, glomerular filtration rate) and possibly improve or slow progression of their kidney disease, although no program could reverse kidney damage ("I'll never be without kidney disease ... it's chronic, it's, it doesn't go away."). Most participants discussed how an exercise program could help them be in better shape, increase strength and energy, improve mobility and weight, and build muscle. Half of the participants stated that the program would improve their motivation for exercise: "That is one of the one of the reasons why I want to be a part of it, because I'm hopeful ... I'll be able to just use that as... a jumping off point for you know, healthy regimens." Participants felt the program could increase knowledge of exercise and kidney disease, and build community, especially among older people where community isolation was more common.

Participants discussed the importance of planning programs that overcame barriers to class attendance like traffic, work hours, and lack of transportation. About half of the participants were willing to try any type of exercise or activity as long it was beneficial to their health. Walking (especially outdoors), the most common response, elliptical machines, stationary bicycles, Zumba or other dance-based exercises, stretching exercises (e.g., Yoga, Barre), weight lifting, games/sports, or interval training were particularly appealing. Participants hoped instructors/exercise trainers would be skilled motivators and empathetic to their health limitations. Although participants understood that trainer should push participants a little, they would be discouraged by someone too strict and rigid ("the drill sergeant"). Trainers should be knowledgeable about CKD: "I could go to class do everything and ... then two weeks later, I can come back and not be able to do anything, and most trainers don't understand that concept because they're trained that your supposed to make gains every single week and that does not work for people who have any type of chronic illness." 


\section{Discussion}

In a racially and ethnically diverse group of people with advanced CKD but not yet on dialysis, we found that participants expressed realistic expectations about the benefits of exercise including potential improvement to their health and physical functioning. None expected exercise to 'cure' existing kidney disease, but many were hoping to delay progression of CKD, maintain mobility, or better withstanding initiation of renal replacement therapy. Health-related factors were both the primary barrier and motivating factor to PA in this study (Fig. 1). These health-related factors have a cyclical relationship with both exercise and CKD, whereby health-related factors: 1. directly affect PA levels thereby affected CKD outcome for the better (increased mobility, slower disease progression) or worse (earlier need for renal replacement therapy, loss of mobility); and 2. are made worse (barriers) or better (motivating factors) by both exercise and CKD. Participants expressed the necessity of exercise programming to accommodate significant physical debility and self-efficacy limitations.

Even though all participants mentioned at least one benefit to and one motivator for exercise and most participants expressed an interest in being more active, few reported a regular activity schedule. These findings are consistent with other studies showing generally low PA levels among people with CKD [2]. The few participants reporting regular PA had very high activity levels (e.g., daily runs), which is consistent with published quantitative data showing that persons with CKD meeting PA guidelines were very active [26].

The results reported here are generally consistent with other studies. One qualitative study among individuals with CKD in the UK, reported similar barriers and motivating factors for PA; however, family support was a key motivating factor for exercise among UK participants, [27] while in this US-based study, participants were motivated by the social interactions exercise could provide. This could reflect a higher social isolation among participants in this study. In an integrative review of the literature on barriers to PA among renal disease patients, low energy level and fatigue were the most frequently cited barriers to PA [28]. This is consistent with what participants reported in this study. Although low energy was not specifically cited, health issues, multimorbidity, medication side effects, and stress-related strains on mental health, all of which can result in physical and/or mental fatigue, were cited as the most significant barrier to exercise.

Although interventions are needed in this high risk population to address low PA levels, [29] few programs have been customized to the specific challenges facing patients with CKD. Participants reported that social support was a major motivating factor for PA. Group-based exercise programs have been shown to improve cardiometobolic health [30-33], and social support could help

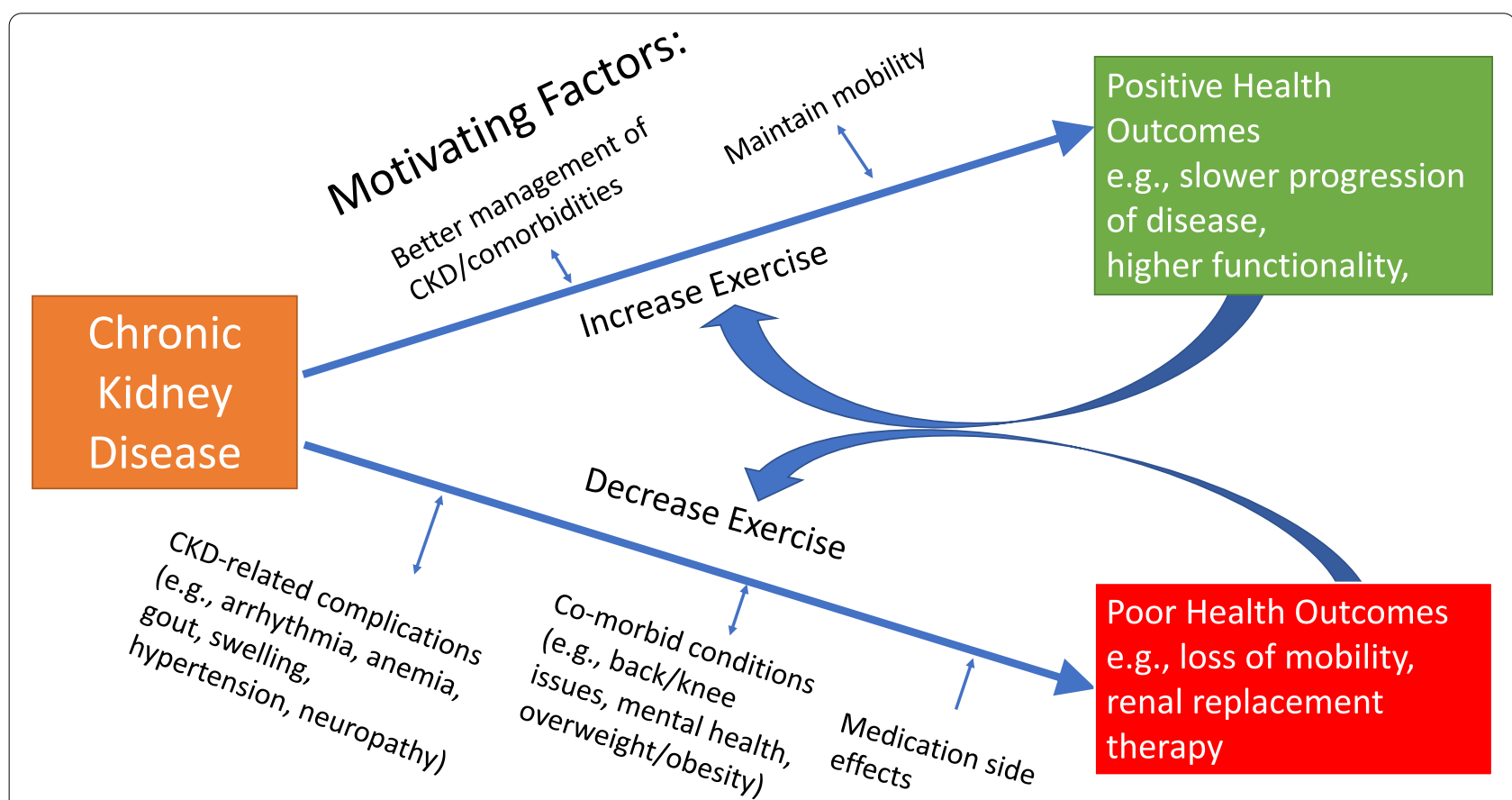

Fig. 1 Health-related Exercise Barriers and Motivators in People with CKD and Their Interconnectivity with Health Outcomes 
mitigate the mental health strain of chronic disease. However, more research is needed to find successful, sustainable and acceptable group-based programs to increase PA in all persons with CKD. Existing trials in this area are limited, focusing primarily on patients on dialysis and on individual exercise [34-37]. CKD programs could benefit from the knowledge gained in proven, group-based programs used in prevention or management or other chronic conditions, where tools like goal setting, problem solving, responding to barriers and challenges, and building social support have been successfully used to improve health behaviors (for example [18, 30, 38, 39]).

Furthermore, participants discussed how existing exercise programs and mobile applications were not responsive to their needs as CKD patients, often applying general exercise advice and feedback, which was not always appropriate to their current realities. Programs, including $\mathrm{m}$-health applications, are needed that take into account patients' health needs, changing energy levels, and multi-morbidities. Participants also reported a reluctance to maintain use of technology-based exercise tools and found existing tools too complicated for those with lower computer literacy. To be successful, technology interventions must respond to the needs of the particular patient population, in this case including an easy-to-use interface, flexible advice that responds to the changing needs and abilities of CKD patients, and promotion of social support. In addition, interventions should build in tools and time to reduce the digital divide within and across their patient population by increasing self-efficacy for technology use, building trust with users, and including sufficient education efforts before asking participants to adopt new technologies [40].

Participants in this and other CKD studies [27] report a lack of specific exercise advice from their medical care providers. Understanding the barriers to and motivations for exercise in this population can help healthcare professionals guide their patients' PA. Exercise advice should be specific (e.g., $30 \mathrm{~min}$ of moderate activity like walking 5 days per week), address barriers (e.g., chair exercises for when mobility is limited), and focus on motivating factors specific to different patients (e.g., physical appearance aspects of exercise for women and longer life for men).

This study has several strengths. In-depth interviews with a diverse population with CKD from two clinics in different regions of the country provides a rich description of the exercise barriers, motivating factors and experiences. Study results could be strengthened by including interviews with non-English speaking patients, who might have a very different experience with care and disease management, and data is needed on patients with early CKD and at non-academic healthcare centers. The goal of these interviews was to collect information for the development of an intervention in the target community, and the discussions focused on topics that would assist in that goal (e.g., understanding experiences and views of physical activity, identifying barriers and facilitators, and discussion planned intervention components). Because of this focus, even though the interview participants were racially and ethnically diverse, there could be additional issues related to race, ethnicity, or other demographic or sociocultural factors that were not identified.

In conclusion, this study showed there is interest in exercise programs for CKD management, provided such programs address important barriers and are responsive to the unique needs of the CKD community. Careful attention needs to be paid to the likely severe physical disability in a majority of participants, setting realistic expectations and logistical barriers. Programs should not rely solely on technology, but could integrate technology into a program that promotes social support and includes preferred motivators like goal setting and supportive instructors.

\section{Supplementary Information}

The online version contains supplementary material available at https://doi. org/10.1186/s12882-021-02591-9.

Additional file 1.

Additional file 2.

\section{Acknowledgements}

The authors wish to acknowledge Lani Demchak who was instrumental in conducting this work.

Authors' contributions

SA and FL developed the study design; MBW guided on qualitative design, trained interviewers, conducted the qualitative analysis, and was the primary author; $\mathrm{ABi}$ and $\mathrm{AB}$ performed participant interviews, and SZ provided key content to the manuscript. Each author contributed important intellectual content during manuscript drafting or revision, assisted in code development and data interpretation, accepts personal accountability for the author's own contributions, and agrees to ensure that questions pertaining to the accuracy or integrity of any portion of the work are appropriately investigated and resolved. The author(s) read and approved the final manuscript.

\section{Funding}

The study was supported by a grant for Applied Pragmatic Clinical Research by the Normon S. Coplon Satellite Grant Committee. Satellite Healthcare is a non- profit hemodialysis provider. MBW and FL were partially supported by NIDDK P30DK111024. Dr. Anand was supported by NIDDK K23DK101826. The funding organizations had no role in any part of the study including data collection, analysis, and reporting

\section{Availability of data and materials}

All data generated or analyzed during this study are included in this published article (please see Supplements 1 and 2 for the interview guide and deidentified verbatim transcripts, respectively). 


\section{Declarations}

\section{Ethics approval and consent to participate}

The study was approved by Emory University (IRB\#00099894) and Stanford University (IRB\#43198) Institutional Review Boards (IRB), and all methods were performed in accordance with the relevant IRB guidelines and regulations. Participants provided written informed consent before study enrollment and additional oral consent before their interview.

\section{Consent for publication}

Not applicable.

\section{Competing interests}

\section{None declared.}

\section{Author details}

${ }^{1}$ Hubert Department of Global Health, Rollins School of Public Health, Emory University, 1518 Clifton Road, NE, MS 1518-002-7BB, Atlanta, GA, USA. ${ }^{2}$ Division of Nephrology, Stanford University School of Medicine, Stanford, USA. ${ }^{3}$ Exercise is Medicine Global Research and Collaboration Center, Rollins School of Public Health, Emory University, Atlanta, GA, USA

Received: 10 February 2021 Accepted: 26 October 2021

Published online: 10 November 2021

\section{References}

1. Shlipak MG, Fried LF, Cushman M, Manolio TA, Peterson D, Stehman-Breen $C$, et al. Cardiovascular mortality risk in chronic kidney disease: comparison of traditional and novel risk factors. JAMA. 2005;293(14):1737-45.

2. Beddhu S, Baird BC, Zitterkoph J, Neilson J, Greene T. Physical activity and mortality in chronic kidney disease (NHANES III). Clin J Am Soc Nephrol. 2009:4(12):1901-6.

3. Tsai YC, Chen HM, Hsiao SM, Chen CS, Lin MY, Chiu YW, et al. Association of physical activity with cardiovascular and renal outcomes and quality of life in chronic kidney disease. PLoS One. 2017:12(8):e0183642.

4. Heiwe $\mathrm{S}$, Jacobson SH. Exercise training for adults with chronic kidney disease. Cochrane Database Syst Rev. 2011;10:CD003236.

5. Kurella Tamura M, Covinsky KE, Chertow GM, Yaffe K, Landefeld CS, McCulloch CE. Functional status of elderly adults before and after initiation of dialysis. N Engl J Med. 2009;361(16):1539-47.

6. Mustata S, Groeneveld S, Davidson W, Ford G, Kiland K, Manns B. Effects of exercise training on physical impairment, arterial stiffness and healthrelated quality of life in patients with chronic kidney disease: a pilot study. Int Urol Nephrol. 2011:43(4):1133-41.

7. Stevens PE, Levin A, Members KDIGOCKDGDWG. Evaluation and management of chronic kidney disease: synopsis of the kidney disease: improving global outcomes 2012 clinical practice guideline. Ann Intern Med. 2013;158(11):825-30.

8. Johansen KL, Chertow GM, Kutner NG, Dalrymple LS, Grimes BA, Kaysen GA. Low level of self-reported physical activity in ambulatory patients new to dialysis. Kidney Int. 2010;78(11):1164-70.

9. Delgado C, Johansen KL. Barriers to exercise participation among dialysis patients. Nephrol Dial Transplant. 2012;27(3):1152-7.

10. Painter P, Clark L, Olausson J. Physical function and physical activity assessment and promotion in the hemodialysis clinic: a qualitative study. Am J Kidney Dis. 2014;64(3):425-33.

11. Thompson S, Tonelli M, Klarenbach S, Molzahn A. A qualitative study to explore patient and staff perceptions of Intradialytic exercise. Clin J Am Soc Nephrol. 2016;11(6):1024-33.

12. Jhamb M, McNulty ML, Ingalsbe G, Childers JW, Schell J, Conroy MB, et al. Knowledge, barriers and facilitators of exercise in dialysis patients: a qualitative study of patients, staff and nephrologists. BMC Nephrol. 2016;17(1):192

13. Komatsu H, Yagasaki K, Saito Y, Oguma Y. Regular group exercise contributes to balanced health in older adults in Japan: a qualitative study. BMC Geriatr. 2017:17(1):190.
14. Yorks DM, Frothingham CA, Schuenke MD. Effects of group fitness classes on stress and quality of life of medical students. J Am Osteopath Assoc. 2017:117(11):e17-25.

15. Romeo A, Edney S, Plotnikoff R, Curtis R, Ryan J, Sanders I, et al. Can smartphone apps increase physical activity? Systematic review and Metaanalysis. J Med Internet Res. 2019;21(3):e12053.

16. Brickwood KJ, Watson G, O'Brien J, Williams AD. Consumer-based wearable activity trackers increase physical activity participation: systematic review and Meta-analysis. JMIR Mhealth Uhealth. 2019;7(4):e11819.

17. Lobelo F, Kelli HM, Tejedor SC, Pratt M, McConnell MV, Martin SS, et al. The wild wild west: a framework to integrate $\mathrm{mHealth}$ software applications and Wearables to support physical activity assessment, counseling and interventions for cardiovascular disease risk reduction. Prog Cardiovasc Dis. 2016:58(6):584-94.

18. Nilsson BB, Westheim A, Risberg MA. Effects of group-based high-intensity aerobic interval training in patients with chronic heart failure. Am J Cardiol. 2008;102(10):1361-5.

19. MacPherson MM, Merry KJ, Locke SR, Jung ME. Effects of Mobile health prompts on self-monitoring and exercise behaviors following a Diabetes prevention program: secondary analysis from a randomized controlled trial. JMIR Mhealth Uhealth. 2019;7(9):e12956.

20. Changizi M, Kaveh MH. Effectiveness of the mHealth technology in improvement of healthy behaviors in an elderly population-a systematic review. Mhealth. 2017:3:51.

21. Jagannathan R, Ziolkowski SL, Weber MB, Cobb J, Pham N, Long J, et al. Physical activity promotion for patients transitioning to dialysis using the "exercise is medicine" framework: a multi-center randomized pragmatic trial (EIM-CKD trial) protocol. BMC Nephrol. 2018;19(1):230.

22. Katzmarzyk PT, Lee IM, Martin CK, Blair SN. Epidemiology of physical activity and exercise training in the United States. Prog Cardiovasc Dis. 2017:60(1):3-10.

23. American Diabetes A. Standards of medical Care in Diabetes-2020 abridged for primary care providers. Clin Diabetes. 2020;38(1):10-38.

24. American Diabetes A. 3. Prevention or delay of type 2 Diabetes: standards of medical Care in Diabetes-2020. Diabetes Care. 2020:43(Suppl 1):S32-6.

25. Hennink MM, Kaiser BN, Marconi VC. Code saturation versus meaning saturation: how many interviews are enough? Qual Health Res. 2017:27(4):591-608

26. Fassett RG, Robertson IK, Geraghty DP, Ball MJ, Burton NW, Coombes JS. Physical activity levels in patients with chronic kidney disease entering the LORD trial. Med Sci Sports Exerc. 2009;41(5):985-91.

27. Clarke AL, Young HM, Hull KL, Hudson N, Burton JO, Smith AC. Motivations and barriers to exercise in chronic kidney disease: a qualitative study. Nephrol Dial Transplant. 2015;30(11):1885-92.

28. Hannan M, Bronas UG. Barriers to exercise for patients with renal disease: an integrative review. J Nephrol. 2017;30(6):729-41.

29. Howden EJ, Coombes JS, Isbel NM. The role of exercise training in the management of chronic kidney disease. Curr Opin Nephrol Hypertens. 2015:24(6):480-7.

30. Ely EK, Gruss SM, Luman ET, Gregg EW, Ali MK, Nhim K, et al. A National Effort to prevent type 2 Diabetes: participant-level evaluation of CDC's national Diabetes prevention program. Diabetes Care. 2017;40(10):13311341. https://doi.org/10.2337/dc16-2099.

31. Hogan BE, Linden W, Najarian B. Social support interventions: do they work? Clin Psychol Rev. 2002;22(3):383-442.

32. Kim C, McEwen LN, Kieffer EC, Herman WH, Piette JD. Self-efficacy, social support, and associations with physical activity and body mass index among women with histories of gestational diabetes mellitus. Diabetes Educ. 2008;34(4):719-28.

33. Wing RR, Jeffery RW. Benefits of recruiting participants with friends and increasing social support for weight loss and maintenance. J Consult Clin Psychol. 1999;67(1):132-8.

34. Manfredini F, Mallamaci F, D'Arrigo G, Baggetta R, Bolignano D, Torino C, et al. Exercise in patients on Dialysis: a multicenter, randomized clinical trial. J Am Soc Nephrol. 2017;28(4):1259-68.

35. Rossi AP, Burris DD, Lucas FL, Crocker GA, Wasserman JC. Effects of a renal rehabilitation exercise program in patients with CKD: a randomized, controlled trial. Clin J Am Soc Nephrol. 2014;9(12):2052-8.

36. Hellberg M, Hoglund P, Svensson P, Clyne N. Randomized controlled trial of exercise in CKD-the RENEXC study. Kidney Int Rep. 2019:4(7):963-76. 
37. Hiraki K, Shibagaki Y, Izawa KP, Hotta C, Wakamiya A, Sakurada T, et al. Effects of home-based exercise on pre-dialysis chronic kidney disease patients: a randomized pilot and feasibility trial. BMC Nephrol. 2017;18(1):198.

38. Nhim K, Gruss SM, Porterfield DS, Jacobs S, Elkins W, Luman ET, et al, Using a RE-AIM framework to identify promising practices in National Diabetes Prevention Program implementation. Implement Sci. 2019;14(1):81

39. Nourian M, Askari G, Golshiri P, Miraghajani M, Shokri S, Arab A. Effect of lifestyle modification education based on health belief model in overweight/obese patients with non-alcoholic fatty liver disease: a parallel randomized controlled clinical trial. Clin Nutr ESPEN. 2020;38:236-41.

40. Fox G, Connolly R. Mobile health technology Apoption across generations: narrowing the digital divide. Inf Syst J. 2018;28:995-1019.

\section{Publisher's Note}

Springer Nature remains neutral with regard to jurisdictional claims in published maps and institutional affiliations.
Ready to submit your research? Choose BMC and benefit from:

- fast, convenient online submission

- thorough peer review by experienced researchers in your field

- rapid publication on acceptance

- support for research data, including large and complex data types

- gold Open Access which fosters wider collaboration and increased citations

- maximum visibility for your research: over $100 \mathrm{M}$ website views per year

At BMC, research is always in progress.

Learn more biomedcentral.com/submissions 